\title{
SERO-SURVEILLANCE OF BRUCELLOSIS IN CATTLE OF CHITWAN DISTRICT, NEPAL
}

\author{
Sabita Subedi $^{{ }^{*}}$, Meera Prajapati ${ }^{2}$ and Bhojan Dhakal ${ }^{3}$ \\ ${ }^{1}$ Institute of Agriculture and Animal Science, Internee, Rampur, Chitwan, Nepal \\ ${ }^{2}$ Animal Health Research Division, Nepal Agricultural Research Council (NARC), Khumaltar, Kathmandu, Nepal \\ ${ }^{3}$ National Animal Science Research Institute (NASRI), Nepal Agricultural Research Council NARC, Khumaltar, Kathmandu, Nepal \\ *Corresponding author's email: sabitasubedi22@gmail.com
}

\begin{abstract}
A cross sectional study was conducted in Eastern and Western parts of Chitwan district from November 2015 to April, 2016 in two parts, the social study followed by biological to determine and compare the prevalence, distribution of antibodies, and level of awareness of farmers against Brucella abortus in cattle of the two regions of same district. Altogether blood samples of 92 cattle were taken for detection of Brucella antibodies by using RBPT test and the positive samples were further retested by Indirect ELISA test through ID Vet iELISA kit 2016. The samples which showed positive on both tests were confirmed as seropositive. Chi -square test and Fisher Exact test was used to find out the association between various variables. The result showed that $14.13 \%$ (13/92) and 10.86\% (10/92) sample were positive by RBPT and iELISA test respectively. There was no significant prevalence differences $(\mathrm{p}>0.05)$ on location, age group, breed type, and method of service (artificial and natural) used in cattle. Comparing abortion with prevalence of Brucellosis, there was significant differences $(p<0.05)$ in the result of both RBPT and iELISA test. Inferring from this result, there is association between the abortion and occurrence of Brucellosis. The higher significant prevalence differences $(\mathrm{p}<0.01)$ was according to the time of abortion where higher seropositivity was obtained in the cattle aborted on $5-7^{\text {th }}$ month of pregnancy and cattle of $3^{\text {rd }}$ parity. The study showed the existence of Brucellosis in Chitwan district with no adoption of any preventive measures against this disease, so here is current need of the strategies for its prevention and control in order to mitigate such overwhelming situation.
\end{abstract}

Keywords: Brucellosis; Cattle; Prevalence; Chitwan; RBPT; iELISA test

\section{Background}

Nepal is an agricultural country in which the livestock sector contributes 24 percent of the total agricultural GDP (AGDP) (ADS, 2014). Around 73 million cattle are reared in Nepal in which the Chitwan which is considered as a pocket area of milk production, contains 74609 cattle (DLSO 2071/72) producing 250,000 Liters. Feed, housing, prevalence of diseases, its prevention and control plays the crucial role for their better performance. But the presence of infectious and non-infectious diseases in the livestock, can have direct impact on the health of animal, animal stake holders as well as on the economy.

Among the different diseases on the livestock, Brucellosis is one of the most important and widespread zoonotic diseases caused by Brucella spp. resulting significant economic losses due to decreased in calving percentage, delayed in calving, culling for infertility, decreased in milk production, abortions, stillbirth, birth of weak calves and loss of labors spent in infected animal cost of treatment, and can infect people too (Poester et al., 2002; Dermott et al., 2002; Ocholi et al., 2004; Adamu, 2009). Infection in bulls also causes orchitis, epididymitis, seminal vesiculitis and hygroma (Kumi-Diaka et al., 1980; Godfroid et al., 2004).

On the one hand, this disease is easily transmissible disease transmitted through direct contact when handling Brucella infected products such as placenta, fetus, fetal fluids and vaginal discharges with bruised or even intact skin (Grillo et al., 1997). Human consuming unpasteurized milk from an infected animal are also under risk. On the other hand majority of farmers in Chitwan believe cows as the symbol of Goddess, don't believe in slaughtering of them, leave the aborted, infertile cattle in jungle, road or any accessible area. Once the animal is infected, it may continue to shed bacteria and remain as a source of infection to others for longer period (Corbel, 2006). So the animal handlers as well as other animal species who are in direct unprotected 
contact with infected animals and unavailability of Brucella vaccination in Nepal increase the chance of infecting with this disease.

Few researches such as Khanal et al., (1997/98), Joshi et al.,(2005), Poudel (2006), Pyakurel and Mishra (1997) has been done showing the prevalence of Brucellosis but the study is not sufficient to gather the actual situation in Chitwan. Hence, this research work on Brucellosis on cattle in Chitwan district is carried out in order to fill this information gap, level of awareness of the farmers regarding the disease as well as adopted strategies for its prevention and control and to provide baseline data to help veterinarians, animal scientists, cattle owners and handlers and to assist policy makers in making policies that will help to prevent and control the disease. So this study is done with the objective of determining Sero-surveillance of Brucellosis infection in cattle in Chitwan district.

\section{Materials and Method}

The Cross sectional study was carried out during a period of November 2015 to April, 2016. Two areas of Eastern Chitwan named Chainpur and Parsa municipality in Eastern Chitwan and three areas Patihani, Geetanagar and Jagatpur under Bharatpur municipality in Western Chitwan were selected for the study. Out of total cattle, purposive sampling is done and blood sample of 92 cattle were collected along with the information about farmers and cattle was taken. Questionnaire survey was also conducted. These collected blood samples were kept in Ice box for maintaining cold chain. These were taken to Veterinary teaching hospital, Rampur for the separation of the serum. Serum separation was done by centrifuging blood sample at $10,000 \mathrm{rpm}$ for 15 minutes and kept in deep freeze condition until transportation for test. These samples were taken Animal Health Research Division Laboratory by maintaining cold chain and put under deep freeze until test was carried. The sample is tested by two tests: The RBPT and Indirect ELISA test in order to determine the presence of antibodies of Brucella. Prevalence was calculated by percentage of the positive cases considering all the subjects under study and data were analyzed by using descriptive statistics at 5\% significance level. The collected data were analyzed by using MS- Excel 2007and SPSS Version 16.The association of the factors under study was tested by Chi-square test and Fischer's exact test.

\section{Results}

\section{Region Wise Prevalence of Brucellosis in Cattle at Chitwan District}

Among 50 cattle tested from Eastern Chitwan, 10 (10.87\%) were found to be positive and $40(43.38 \%)$ negative by RBPT while 7 (7.61) were positive, 41(44.57\%) negative and $3(3.26 \%)$ were doubtful for Brucella by iELISA test.
Similarly 43 cattle tested from Western Chitwan, 3(3.26\%) were found positive and 39(42.39\%) negative by RBPT while $3(3.26 \%)$ were found positive and $39(42.39 \%)$ negative from iELISA test which is shown on Table 1. This seems to be non-significant $(p>0.05)$ at $95 \%$ level of confidence i.e. there is no significant difference in the occurrence of brucellosis in two different region of Chitwan district.

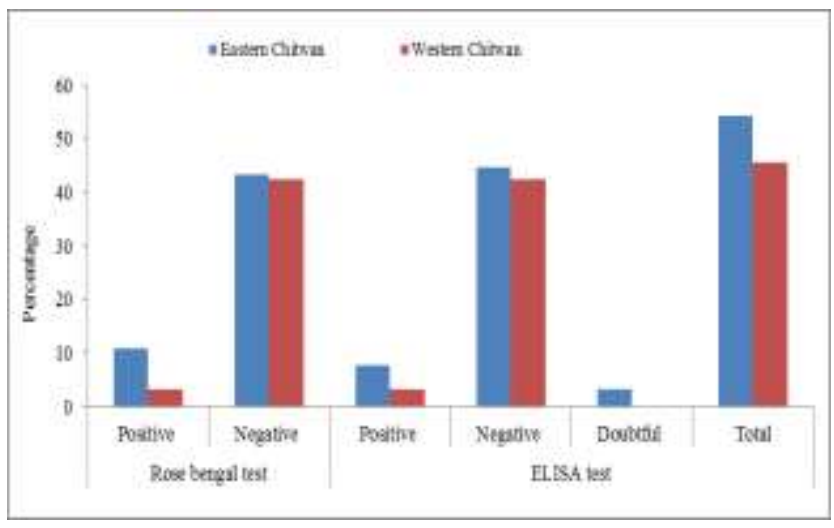

Fig. 1: Region wise prevalence of Brucellosis in cattle at Chitwan

\section{Age Wise Prevalence of Brucellosis in Cattle at Chitwan District}

Age wise four classes were made. The first class being of cattle between (3-5) year, $2^{\text {nd }}$ class (5-7), third (7-9) and fourth (9-above) years of cattle. Out of total cattle, age group of (3-5) year only $1.09 \%$ (1/92) was positive by RBPT and $1.09 \%$ (1/92) by iELISA test. On Age group of (5-7) year, 5\% showed positive results by RBPTs and 3\% shows the positive result by iELISA test. The age group (79) year, $6 \%$ cattle showed positive through both RBPT and iELISA test (Fig. 2). In the same way the age group (9 year above), $0 \%$ was positive by both RBPT and iELISA test. There was no statistically significant difference in age wise prevalence of brucellosis in cattle $(\mathrm{p}>0.05)$.

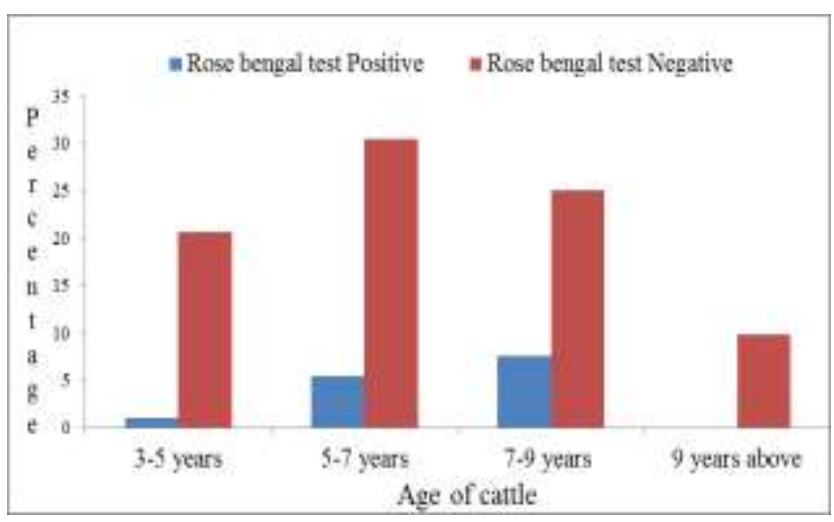

Fig. 2: Age wise prevalence of Brucellosis in cattle at Chitwan district (Rose Bengal test). 
Table 1: Study of prevalence Brucellosis in cattle based on various parameters

\begin{tabular}{|c|c|c|c|c|c|c|}
\hline \multicolumn{2}{|l|}{ Parameters } & \multicolumn{2}{|c|}{ RBPT } & \multicolumn{3}{|c|}{ iELISA } \\
\hline \multirow{3}{*}{ Region } & & Positive & Negative & Positive & Negative & Not sure \\
\hline & Eastern Chitwan & $10(10.87)$ & $40(43.38)$ & $7(7.61)$ & $40(44.57)$ & $3(3.26)$ \\
\hline & Western Chitwan & $3(3.26)$ & $39(42.39)$ & $3(3.26)$ & $39(42.39)$ & $0(0.00)$ \\
\hline \multicolumn{2}{|c|}{ Total Chi-square probability } & \multicolumn{2}{|l|}{0.078} & \multicolumn{3}{|l|}{0.139} \\
\hline \multirow{4}{*}{ Age } & $3-5$ years & $1(1.09)$ & $19(20.65)$ & $1(1.09)$ & $19(20.65)$ & $0(0.00)$ \\
\hline & $5-7$ years & $5(5.43)$ & $28(30.43)$ & $3(3.26)$ & $28(30.43)$ & $2(2.17)$ \\
\hline & $7-9$ years & $7(7.61)$ & $23(25.00)$ & $6(6.12)$ & $23(25.00)$ & $1(1.09)$ \\
\hline & 9 years above & $0(0.00)$ & $9(9.78)$ & $0(0.00)$ & $9(9.78)$ & $0(0.00)$ \\
\hline \multicolumn{2}{|c|}{ Total Chi-square probability } & \multicolumn{2}{|l|}{0.173} & \multicolumn{3}{|l|}{0.375} \\
\hline \multirow[t]{2}{*}{ Breed } & Cross breed & $10(10.04)$ & $43(46.74)$ & $8(8.70)$ & $43(46.74)$ & $2(2.17)$ \\
\hline & Local breed & $3(3.26)$ & $36(39.13)$ & $2(2.17)$ & $36(39.13)$ & $1(1.09)$ \\
\hline \multicolumn{2}{|c|}{ Total Chi-square probability } & \multicolumn{2}{|l|}{0.178} & \multicolumn{3}{|l|}{0.289} \\
\hline \multirow{2}{*}{ Abortion } & aborted & $12(13.04)$ & $32(34.78)$ & $9(9.78)$ & $34(36.96)$ & $2(2.17)$ \\
\hline & Non aborted & $1(1.09)$ & $47(51.09)$ & $0(0.00)$ & $47(51.09)$ & $0(0.00)$ \\
\hline \multicolumn{2}{|c|}{ Total Chi-square probability } & \multicolumn{2}{|l|}{0.001} & \multicolumn{3}{|c|}{0.002} \\
\hline \multirow{5}{*}{ Parity wise } & $1^{\text {st }}$ parity & $0(0.00)$ & $18(19.57)$ & $0(0.00)$ & $18(19.57)$ & $0(0.00)$ \\
\hline & $2^{\text {nd }}$ parity & $2(2.17)$ & $28(30.43)$ & $1(1.09)$ & $28(30.43)$ & $1(1.09)$ \\
\hline & $3^{\text {rd }}$ parity & $5(5.43)$ & $22(23.91)$ & $3(3.26)$ & $5(5.43)$ & $2(2.17)$ \\
\hline & $4^{\text {th }}$ parity & $3(3.26)$ & $6(6.52)$ & $3(3.26)$ & $6(6.52)$ & $0(0.00)$ \\
\hline & $5^{\text {th }}$ parity & $3(3.26)$ & $6(6.52)$ & $3(3.26)$ & $6(6.52)$ & $0(0.00)$ \\
\hline \multicolumn{2}{|c|}{ Total Chi-square probability value } & \multicolumn{2}{|l|}{0.025} & \multicolumn{3}{|c|}{0.030} \\
\hline \multirow{4}{*}{ Time of abortion } & $1-5$ month & $1(1.09)$ & $4(4.35)$ & $1(1.09)$ & $4(4.35)$ & $0(0.00)$ \\
\hline & 5-7 month & $10(10.87)$ & $9(9.78)$ & $8(8.70)$ & $9(9.78)$ & $2(2.17)$ \\
\hline & 7 and above & $1(1.09)$ & $20(21.74)$ & $1(1.09)$ & $20(21.74)$ & $0(0.00)$ \\
\hline & No abortion & $1(1.09)$ & $46(50.00)$ & $0(0.00)$ & $46(50.00)$ & $1(1.09)$ \\
\hline \multicolumn{2}{|c|}{ Total Chi-square probability value } & \multicolumn{2}{|l|}{0.000} & \multicolumn{3}{|l|}{0.000} \\
\hline \multirow{3}{*}{ Type of service used } & Natural & $1(1.09)$ & $3(3.26)$ & $0(0.00)$ & $3(3.26)$ & $1(1.09)$ \\
\hline & Artificial & $11(11.96)$ & $75(81.52)$ & $9(9.78)$ & $75(81.75)$ & $2(2.17)$ \\
\hline & Both & $1(1.09)$ & $191.09)$ & $1(1.09)$ & $1(1.09)$ & $0(0.00)$ \\
\hline \multicolumn{2}{|c|}{ Total Chi-square probability value } & \multicolumn{2}{|l|}{0.267} & 0.045 & & \\
\hline
\end{tabular}

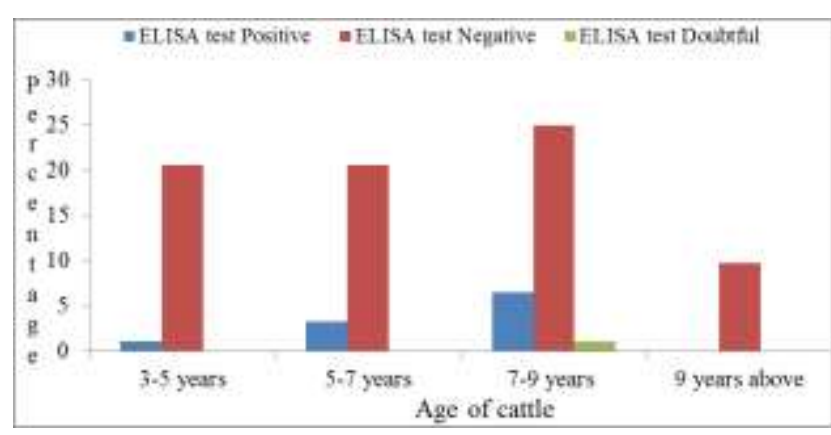

Fig. 3: Age wise prevalence of Brucellosis in cattle at Chitwan district (ELISA test)

\section{Breed Wise Prevalence of Brucellosis by Both Tests}

Out of the total (92) cattle tested, 53 cattle were of Cross breed and 39 were local breed where $10.09 \%$ positive results was seen on Crossbreed cattle by RBPT and $8.70 \%$ positive from iELISA test. In case of local breed $3 \%$ is positive from the RBPT and $2 \%$ is positive from the iELISA test. There was statistically no difference in Breed wise prevalence of brucellosis in cattle $(\mathrm{p}>0.05)$.

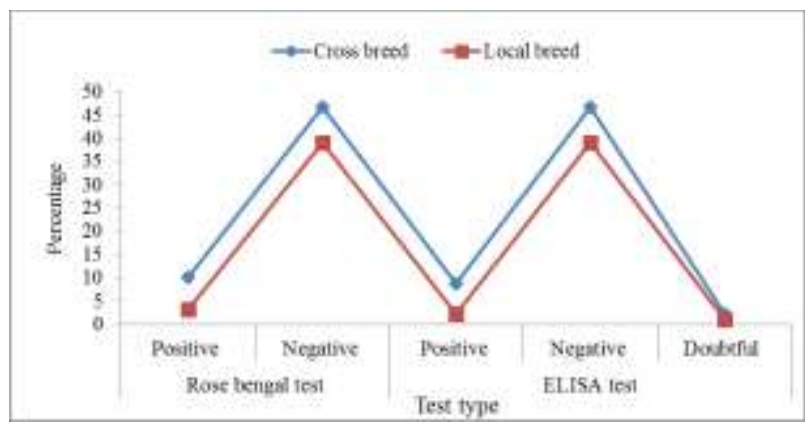

Fig. 4: Breed wise prevalence of Brucellosis by both test

Abortion Wise Prevalence of Brucellosis by Both Tests

Among the total cattle tested they were divided in to aborted and non-aborted one. Out of total cattle, $12 \%$ aborted cattle shows the positive result by the RBPT where $9 \%$ shows the positive results by iELISA test .In the case of non-aborted cattle, $1 \%$ shows the positive result by RBPT where the 
none of the non-aborted cattle shows the positive result. There was statistically significant difference in abortion wise prevalence of brucellosis in cattle $(p<0.05)$ from both mentioned serological test. Figure 4 Breed wise prevalence of Brucellosis by both test (Table 4)

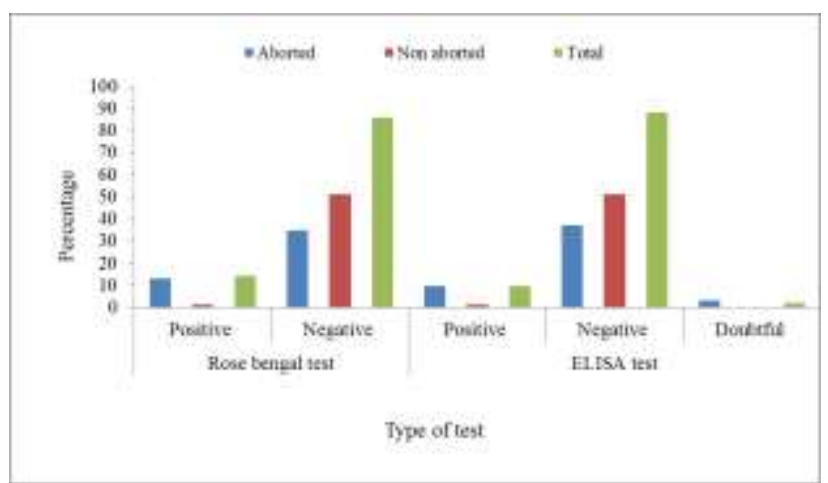

Fig. 5: Abortion wise prevalence of Brucellosis by both tests

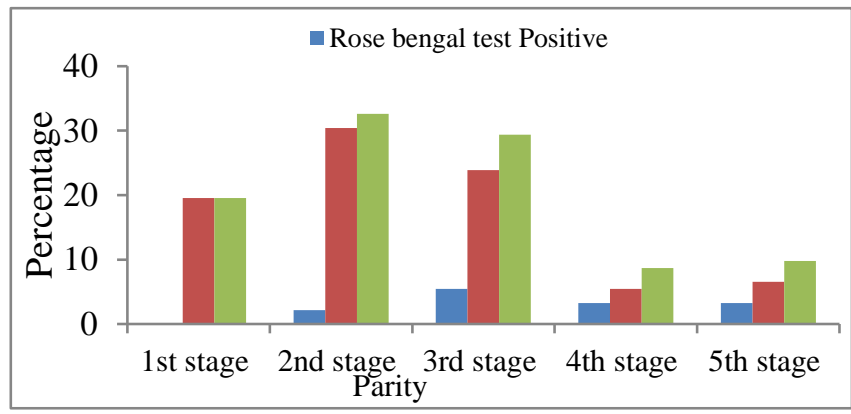

Fig. 6: Parity wise prevalence of Brucellosis by Rose Bengal test

\section{Parity Wise Prevalence of Brucellosis by Both Tests}

The parity wise prevalence is done on cattle at Chitwan district. The prevalence $\%$ of $1^{\text {st }}, 2^{\text {nd }}, 3^{\text {rd }}, 4^{\text {th }}$ and $5^{\text {th }}$ was different in RBPT and iELISA test where there was significant differences between the parity wise prevalence of brucellosis by both RBPT and iELISA test where $\mathrm{p}$ value was less than 0.05 .

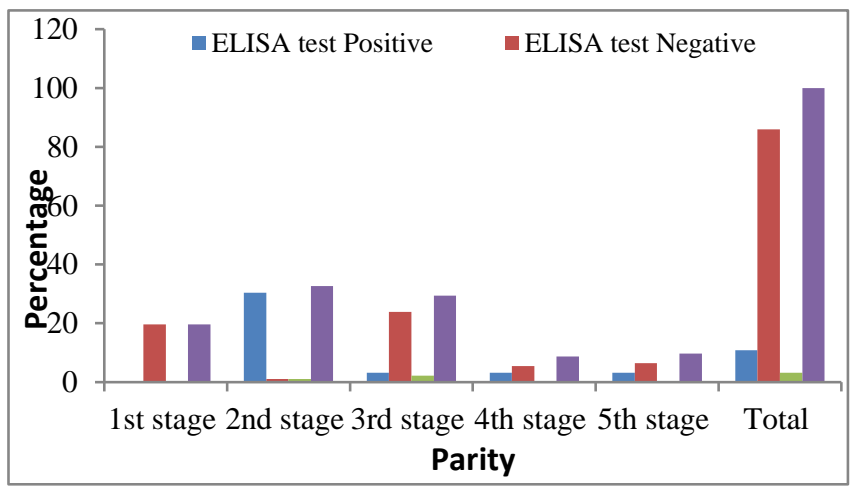

Fig 7: Parity wise prevalence of Brucellosis by ELISA test

\section{Time of Abortion Wise Prevalence of Brucellosis by Both} Tests

On the basis of time of abortion the prevalence of brucellosis was being analyzed. The cattle having abortion on 5-7 month showed the higher prevalence i.e. $10.87 \%$ through RBPT and 9\% through the iELISA test while the lowest prevalence was on the non -aborted cattle with $1 \%$ positive by RBPT and $0 \%$ prevalence from the iELISA test. There was highly significant differences on the time of abortion wise prevalence of brucellosis i.e., $(\mathrm{p}=0.00)$ from both mentioned serological tests.

\section{On the Basis of Type of Service Used}

On the basis of type of service used no significant ( $p>0.05)$ differences occurs between the Natural and Artificial type of services by the RBPT while the iELISA test showed significant differences $(\mathrm{p}<0.05)$ between these two type of services.

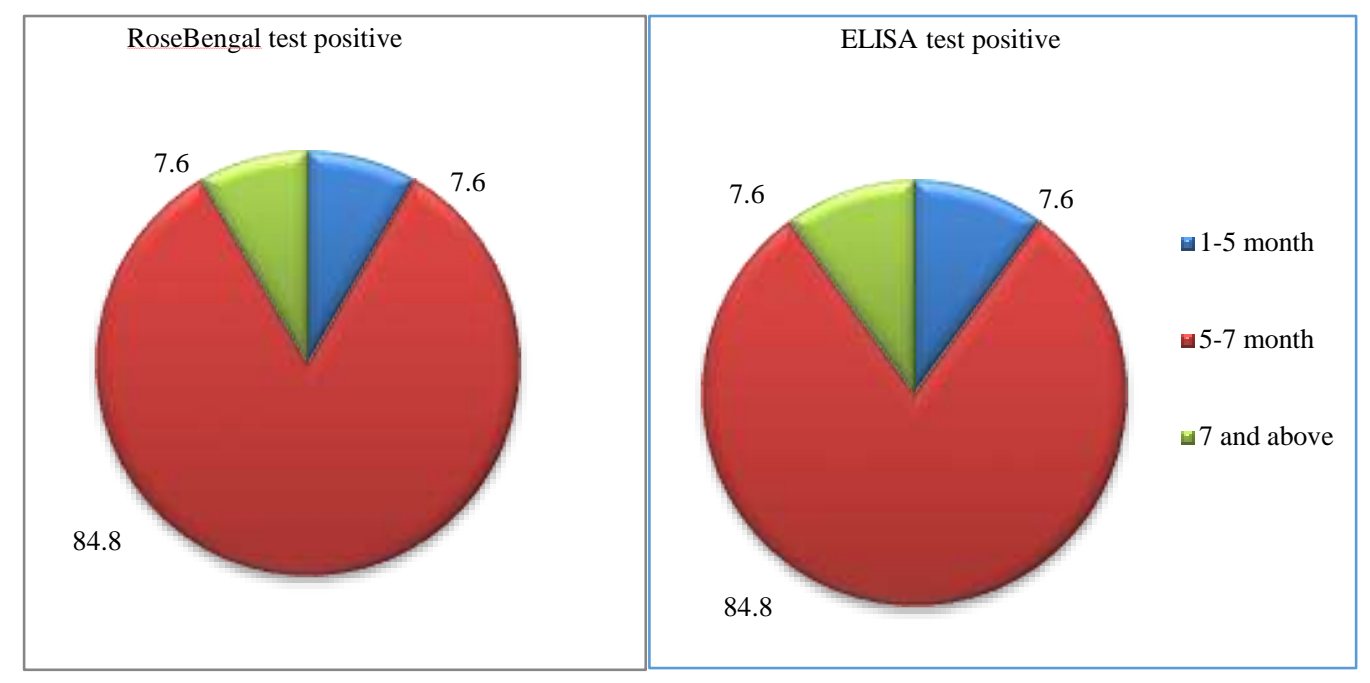

Fig. 8 Time of abortion wise prevalence of Brucellosis by both tests 


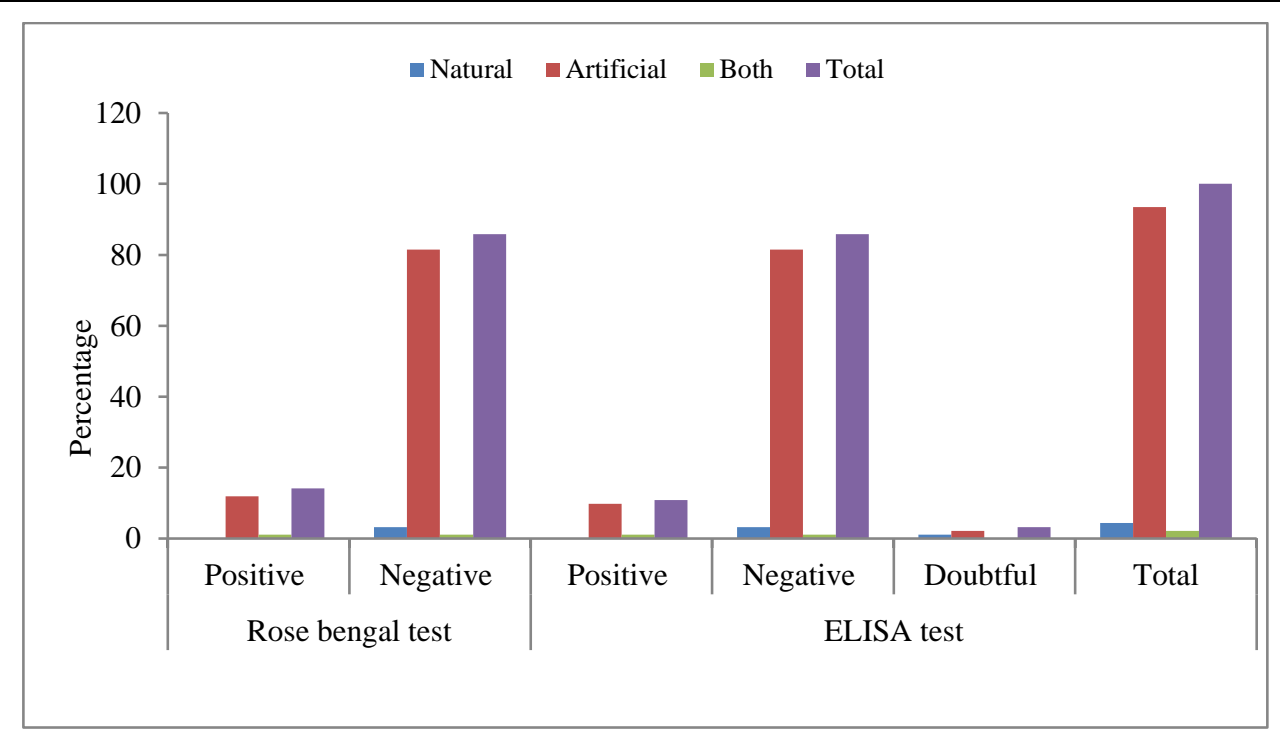

Fig. 9: On the basis of type of service used

\section{Discussion}

The RBPT showed a higher prevalence over iELISA for serum samples which is collected from the district studied. This might be due to the differences in specificity and sensitivity between the two tests, as reported by Poester $e t$ al. (2002) who found the sensitivity and specificity of RBPT to be $100 \%$ in natural infections compared with iELISA at $98.2 \%$ and $98.6 \%$ respectively. However the major disadvantages of the RBPT is that the antibodies from other antibacterial infections like Yersinia enterocolotica and salmonella can cross react with smooth lipopolysaccharides, therefore misleading somehow can occur as well as it also does not distinguish between vaccinated and infected animals (Radostits et al., 2000). In this study there is statistically no difference $p>0.05$ in the performance of two tests. Since animals showing positive through RBPT is again tested by iELISA for the best results. The animals which showed seropositive on both tests were considered as true positive. In this study we found an overall prevalence $14.13 \%$ (13/92) and $10.86 \%$ (10/92) in Chitwan district by RBPT and iELISA test respectively. Out of 13 sample shown positive by RBPT, 3 sample shows the doubtful by the iELISA test. Our study supports to the result of Mishra et al. (2009) when done by RBPT Test, only 9 samples (i.e. $15 \%$ ) revealed to positive to the RBPT reagent. However this findings is higher than Pradhan (1996), a serosurveillance for brucellosis in cattle and buffaloes of Chitwan district. Out of 1126 female cattle, 42 (3.37\%) cattle samples were found positive in plate agglutination test. This may be due to the larger sample size, different in tests used and less disease prevalence in previous years. Similarly this finding is higher than the Khanal et al. (1997/98) in Chitwan and Eastern Terai of Nepal where prevalence rate was obtained to be $1.5 \%(2 / 131)$. This could be because of smaller sample size and increased disease emergence in recent years than previous years. Apart from this, this finding Lower than Mishra et al. (2009) 14/60 samples showed positive to brucellosis by Milk Ring Test. It means $23.22 \%$ of sample revealed positive to the disease. This might be due to the difference in the test and number of sample used. In the same way, this finding is lower than the Pandeya (2013), where Prevalence of brucellosis in cattle is $32 \%$, in Kailali district by using Plate Agglutination test. This might be due o difference in geographical region, sample size and the test used for diagnosis

This finding showed no significant differences in prevalence between two regions i.e. Eastern and Western region this might be due to the same geography, climate as well as overall similar cattle management adopted by the farmers.In this research although the age wise nonsignificant result is observed seropositivity is associated with age in which the cattle above 5 years shows higher seropositivity than below 5 year. This observation is in agreement with Oloffs et al. (1998), Bekele et al. (2000) and Tesfaye (2003), Mai et al. (2012) Junaidu et al. (2011) with similar results that indicate a higher prevalence in animals above six years of age. It has been reported that susceptibility of cattle to $B$. abortus infection is influenced by age of the individual animal (Radostits et al., 2000). Younger animals tend to be more resistant to infection and frequently clear infections, although latent infections do occur (Walker, 1999). Sexually mature and pregnant cattle are more susceptible to infection with the organism than sexually immature cattle of either sex (Radostits et al., 2000) while Shome et al. (2014) showed low in young (1$2 \mathrm{yrs}$ ) and older age group of animals ( $\geq 8 \mathrm{yrs}$.) than in the age groups of 2 to 8 yrs. which also supports my result.

Through this finding, the aborted cattle shows the high seropositivity than the non-aborted one. From this result the abortion is the important signs which is associated with Brucellosis. This research supports the Makita et al. (2011) where the aborted cattle shows the higher seropositivity 
than the non-aborted one. The prevalence rate of brucellosis on aborted was $16 \%$ and non- aborted was only $4.6 \%$. Similarly this findings supports to Tolosa (2004), significant association between brucellosis and occurrence of previous abortion $(\mathrm{p}<0.001)$. This research shows the association between the time of abortion and brucellosis in which the cattle aborted on (5-6) months shows higher seropositivity which agrees the (Radostits et al., 2000) which explains that in highly susceptible non-vaccinated pregnant cattle, abortion after the 5th month of pregnancy is cardinal feature of the disease (Radostits et al., 2000).

\section{Conclusion}

Comparing this result with the previous ones the result showed that the Brucellosis is one of the major problems increasing in higher rate. In this research $12 \%$ aborted cattle shows the positive result by the RBPT where $9 \%$ showed the positive results by iELISA test. The aborted cattle showed the high seropositivity than the non-aborted one. From this result the abortion is the important signs which is associated with Brucellosis. This research shows the association between the time of abortion and brucellosis in which the cattle aborted on (5-6) months shows higher seropositivity i.e., There is association between Brucellosis and this particular gestation months. Apart from this result, in Nepal, majority of farmers as well as animal handlers don't adopt safety measures knowingly or unknowingly for the protection from diseases as well as no availability of vaccination against brucellosis which can be a leading problem in nearby future. So the timely formulation and implementation of prevention and control strategy is the current need. So there is need of Governmental level strategies which will be fruitful and reliable for the prevention and control of disease.

\section{Acknowledgement}

This research project was funded by Internship Advisory Committee, Institute of Agriculture and Animal Science (IAAS), Rampur, Chitwan, Nepal. We are thankful to District Livestock Service Office (DLSO) helping during sample collection. Our sincere gratitude to all the staffs of Animal Health Research Division (AHRD) for their cooperation in lab activities.

\section{References}

Adamu NB (2009) Epidemiology of Brucella Infection in Ruminants and Humans and its Public Health Implication in Borno State, Nigeria. PhD Thesis, Department of Veterinary Public Health and Preventive Medicine, Faculty of Veterinary Medicine, Ahmadu Bello University, Zaria. 231 p.

ADS (2014) Ministry of Agriculture Development, Government of Nepal.

Bekele A, Molla B, Asfaw Y and Yigezu L (2000) Bovine brucellosis: seroepidemiological study in selected farms and ranches in southeastern Ethiopia. Bulletin of Animal Health and Production in Africa 48: 13-17.
Corbel MJ (2006) Brucellosis in human and animals. The World Health Organization in collaboration with the Food and Agriculture Organization of United Nations (FAO) and World Organization for Animal Health (OIE) 2006.

Dermott JJ, Arimi, SM (2002) Brucellosis in sub-Saharan Africa: epidemiology, control and impact. Vet. Microbiol. 90: 111 - 134. DOI: 10.1016/S0378-1135(02)00249-3

Dhakal IP, Jost C, Pakhrin B and Joshi DD (2005) Training on Livestock and Poultry Derived Food Safety and Hygiene in Four Communities in Chitwan District. The Blue Cross Annual Bulletin NVSA 7: 8-14.

DLSO, Annual Report (2071/72) District Livestock Service Office, Chitwan.

Grillo MJ, Barberan M and Blasco JM (1997) Transmission of Brucella melitensis from sheep to lambs. Veterinary Record 140: 602-605. DOI: 10.1136/vr.140.23.602

Joshi DD, Upadhya M and Mishra PN (2005) Brucellosis in animal and human of Chitwan, NZFHRC, Tahachal. pp3748.

Junaidu AU, Oboegbulem S and Salihu MD (2011) Serological survey of brucella antibodies in breeding herd. Journal of Microbiology and Biotechnology Research 1: 60-65.

Khanal DR and Jha VC (1997/98) Study on Bovine abortion and repeat breeding due to Brucellosis in Chitwan and Eastern Terai. Annual Report 1997/98 NARC, AHRD, Tripureshwor, pp 12-17.

Mai HM, Irons CP, Kabir J and Thompson NP (2012) A large sero-prevalence survey of brucellosis in cattle herds under diverse production systems in northern Nigeria. BMC Vet. Res. 8: 144. DOI: 10.1186/1746-6148-8-144

Makita KE, Fèvre M, Waiswa C, Kaboyo W, Eisler MC and Welburn SC (2011b) Evidence based identification of the most important livestock related zoonotic diseases in Kampala, Uganda. Journal of Veterinary Medical Science 73: 991-1000. DOI: 10.1292/jvms.11-0049

Mishra YP, Joshi DD, Gautam SP, Aryal A and Shahi K (2009) Brucellosis in Milking Buffaloes of Bhaktapur Milk shed Areas. Zoonosis Bulletin.

Ocholi RA, Kwaga JK, Ajogi I and Bale JO (2004) phenotypic characterization of Brucella strains isolated from livestock in Nigeria. Vet. Microbiol. 103: 47-53. DOI: 10.1016/j.vetmic.2004.06.012

Oloffs A, Baumann MPO, Afema J and Nakavuma J (1998) Experiences with a strategy to investigate bovine brucellosis in a rural area in Southwest Uganda. Revue Èlev. Méd. Vét. Pays trop. 51(2): 101-105.

Pandeya YR, Joshi DD, Dhakal S et al. (2013) Seroprevalence of brucellosis in different animal species of Kailali district, Nepal. Int. J. Infect. Microbial. 2(1): 22-25. DOI: 10.3126/ijim.v2i1.8005

Poester FP, Gonçalves VSP and Lage AP (2002) Brucellosis in Brazil. Veterinary microbiology 90(1): 55-62. DOI: 10.1016/S0378-1135(02)00245-6 
Poudel A (2006) Seroprevalence of brucellosis in small ruminants in Nepal. B.V.Sc \& A.H., Internship report, IAAS, TU, Nepal.

Pradhan A (1996) Sero prevalence of Brucellosis in cattle and buffaloes in chitwan. Proceeding of first livestock and fisheries research Workshop. PP 227-231.

Pyakurel S and Mishra U (1997) Sero-epidemiological Evidence of Animal brucellosis in Nepal. Bulletin of Veterinary Science and animal husbandry Nepal 6: 1-6.

Radostits OM, Gay Blood CC and Hinchcliff KW (2000) Disease caused by Brucella species. A text book of diseases of Cattle, Sheep Pigs, Goats and Horses. 9th edition London Hercourt Publishers Limited.

Shome R, Padmashree BS, Krithiga N, Triveni K, Sahay S, Shome BR, Singh P and Rahman H (2014) Bovine Brucellosis in organized farms of India - An assessment of diagnostic assays and risk factors. Adv. Anim. Vet. Sci. 2(10): $557-$ 564. DOI: 10.14737/journal.aavs/2014/2.10.557.564

Tesfaye A (2003) Brucellosis in cattle and small ruminant in selected sites of Tigray region, North Ethipia. FVM, AAU, Debre Zeit, DVM thesis.

Tolosa TF (2004) Seroprevalence study of bovine brucellosis and its public health significance in selected sites of Jimma zone, Western Ethiopia, M.S. thesis, Faculty of Veterinary Medicine, Addis Ababa University, Debre Zeit, Ethiopia, 2004.

Walker RL (1999) Brucella. In: Veterinary Microbiology, Hirsh, D.C. and Zee, Y.C. (Eds.), Blackwell Science Inc., Massachusetts, USA, 196-203 pp. 